disease. Gastrectomized patients seem to be especially prone to develop such a myopathy in view of the high frequency of calcium disorders after gastric operations. However, a complete recovery may follow upon treatment with vitamin $\mathrm{D}$. The early diagnosis in the cases is therefore of practical importance.-We are, etc.,

\section{K. Еквом.}

R. HED.

Södersjukhuset and Karolinska Institutet
Stockholm, Sweden.

L. Kirstein.

\section{REPERENCE}

1 Ekbom, K., Hed, R., Kirstein, L., and Aström K. E., Acta med. scand., 1964, 176, 493.

\section{Health Centres}

SIR,-It was refreshing to read (Supplement, 12 June, p. 249) some healthy criticism of the health centre concept-that "sacred cow" of so many who plan for the future of general practice. Dr. G. J. Addis rightly points out that scientific medical practice demands complex equipment for its satisfactory pursuit, and for this nothing smaller than district hospitals can be the focus.

Most authorities will admit that disillusionment among general practitioners can be traced to its origin in their divorce from the hospital service with its clinical incentives and stimulating contacts. When the family doctor returns as an integral part of the staff of a district hospital, having beds of his own under consultant supervision, some consistent future may appear for general practice.

Health centres, on the other hand, differ little in their essence from present-day surgeries. They are still mere coteries of general practitioners equipped indeed with nursing and ancillary staff but a world apart from the scientific atmosphere of a modern hospital. Only when surgeries can be conducted from hospital out-patients departments and the visiting list be arranged as part of that comprehensive service Dr. Addis envisaged (embracing public health, midwifery, care of the chronic sick, geriatric cases, and child-welfare) shall we begin to see a radical new conception of general practice emerge.

If the personal nature of the relationship between the general practitioner and his patient suffers somewhat under this system can we be sure that it is so supremely vital a necessity for the practice of modern medicine? Or is this, too, merely another "sacred cow ?"-I am, etc.,

$$
\text { S. L. HeNDERSON SMITH. }
$$

Huddersfield, Yorks.

\section{“Early Curable Stage” of Rheumatoid Arthritis}

SIR,-Dr. J. W. Todd (29 May, p. 1436) refers to the presidential address given by Mr. Angus Ogilvy at the Annual General Meeting of the British Rheumatism and Arthritis Association. $\mathrm{He}$ reports him correctly as saying that "thousands were suffering needlessly because of a widespread belief, even among some doctors, that little or nothing could be done to mitigate the crippling effects of rheumatism." $\mathrm{Mr}$.
Ogilvy spoke to his members wisely, knowledgeably, and factually. Surely Dr. Todd cannot deny the truth of this statement reported in The Times of 28 April. If he does he can never meet his patients on social occasions or talk to the man or woman who suffers from " rheumatism."

Every day the secretary of the B.R.A.A. receives letters from our members or from the general public asking for advice, saying that their doctors have told them that they have arthritis, that nothing can be done for them. Often this dismal pronouncement has been made after a few questions, and, to the patient, a seemingly cursory examination. The social aspect of their trouble has not been discussed, and they have not been advised to attend hospital for a specialist opinion. They have accepted their family doctor's judgment, and some of them in consequence have suffered years of pain, increasing disability, have lost their jobs, caused distress to their families, and have become " crippled."

The family doctor is only partly to blame. The underlying or main cause of his poor "judgment" is the inadequate teaching, and the improper presentation of the rheumatic diseases by the physicians, whose privilege it is to teach him during his undergraduate days at his teaching hospital. This is possibly aggravated by the desire of many of our specialist colleagues to satisfy the "thirst" of their audiences at B.M.A. lectures and other medical meetings with the presentation of the rheumatoid diseases as intriguing and involved problems in genetics and biochemistry, and the showing of rare cases, which, although he may search for a long time, the family doctor is unlikely to see again. People who suffer from arthritis are seldom, if ever, asked to tell their doctors something of "their side of the story." A willingness on the part of the doctor to spend a few minutes to listen to his patient's story, followed by a clinical examination, a sincere attempt to explain the reason for his symptoms, reassurance, an appreciation of the "social" factors involved, and when uncertain a referral to hospital for " exper advice" would, I am certain, reduce $\mathrm{Mr}$. Ogilvy's thousands by at least one nought.

"If rheumatoid arthritis is not diagnosed early many more do become crippled." This implication is correct. I do not know what would be the "natural history" of the disease in each patient that I saw and discussed with my registrar at this morning's out-patients. We do teach, and I think rightly, that two in ten get well without any disability even if we do nothing, or in spite of our intervention; one in ten or probably less will become "crippled" even if the very best treatment is instituted ; of the remaining seven the "activity" of their disease, their ability to cope with it, and the sort of life that they will be able to live, does depend on our recognition of the disease, preferably in its early phase, and on our giving proper advice which is accepted and carried out, sometimes over many years, by the patient and his doctor.

Dr. Todd's middle-aged lady may well have had a "lesion" localized to the flexor tendon which would have disappeared after a local injection of cortisone, but this would be no excuse for omitting a clinical examination and a "follow-up." Naturally physiotherapy and surgery have only a limited but well-defined role in the management of these patients. This is becoming clear to those of us physicians who in hospital have instituted joint clinics with our orthopaedic, neurological, and plastic surgery colleagues.

"Should she be referred to a psychoanalyst on the assumption that the condition is psychosomatic? This suggestion needs no comment." But it does ; very seldom do I ask the help of a psycho-analyst, but some two years ago I spent a very instructive evening at the Royal Society of Medicine as the guest of the "psycho-somatologists" when they discussed " rheumatoid arthritis." The "follow-up" has already shown its value. The members of our " rheumatoid arthritis" club at Mount Vernon Hospital speak frankly of their "inner aggression" and frustration. Pain and joint swelling have subsided following the "release" of tension by discussion, and sometimes by the breaking of crockery. We are studying these matters in the activities-of-daily-living unit in our occupational-therapy department, but as yet we have not instituted a "double-blind control," and asked for a research grant from our regional board to foot the bill.

As my friend Sir Austin Bradford Hill has often said: "If I have given you the wrong answers it is probably because you have asked me the wrong questions." Dr. Todd's questions and the reason why he asks them demand thought and action.-I am, etc.,

\section{London W.1. FRANCIS BACH,} British Rheumatism and Arthritis Association.

\section{Hyperpyrexia with Antidepressant Drugs}

SIR,-In accord with recent correspondence $^{1-3}$ suggesting that antidepressant therapy may carry the risk of serious hyperpyrexic reaction, I would like to record the following experience :

A 41-year-old nurse was admitted to the hospital in April 1965 in extremis. Relatives stated that she had been in good health several hours previously. The patient was known to have been mildly depressed as a result of her son's disciplinary problems; however, she gave no impression of being despondent. In the past she had dieted for mild obesity and had been known to supplement her diet with amphetamines.

On the night prior to admission the patient had gone on duty and carried out her usual nursing chores in a normal fashion. At 3 a.m. a co-worker had noted that the patient looked "fidgety," and by 6 a.m. the patient was seen to be sweating profusely. She called her husband about one hour later and asked him to meet her as she felt ill. At 7.30 a.m. the patient was still able to converse freely; however, her fidgeting became more pronounced and she was drenched with perspiration. By 9 a.m. she was incoherent, wildly making involuntary, dystonic movements of all extremities, and assuming the opisthotonos posture.

At the time of her admission at 10 a.m. hex pulse was $130 / \mathrm{min}$., blood-pressure $110 / 70 \mathrm{~mm}$. $\mathrm{Hg}$, and respirations $35 / \mathrm{min}$. and stertorous. She maintained opisthotonos, continued to make writhing movements, grimaced, and was unarousable. The pupils were widely dilated and fixed and her fundic arterioles were " threadlike" in appearance. The optic disks were flat. Bilateral Babinski sign was present. Her temperature was $106^{\circ} \mathrm{F}$. $\left(41.1^{\circ} \mathrm{C}\right.$.).

At this time the patient's belongings were searched and a small pill box was found to 
contain two amphetamine tablets (10 mg.) and two Parnate (tranylcypromine) tablets $(10 \mathrm{mg}$ ) Her temperature continued to rise to $109.4^{\circ}$ F. $\left(43^{\circ}\right.$ C.). She was treated by immersion in ice water and the infusion of intravenous salicylate. Therapy was instituted in order to correct the marked dehydration, acidosis, hyperkalaemia, and subsequent hypotension that she suffered. Her blood-pressure remained unobtainable in large doses of metaraminol, but did respond to L-norepinephrine. After about 20 hours of therapy the patient began to support her own blood-pressure, carry on normal respiration, and respond feebly to simple commands. During the second day in the hospital she rallied dramatically and by its end was recognizing and conversing with relatives. Once her sensorium was clear, the patient related a detailed story of her ingestion of amphetamines and tranyl cypromine. She had apparently been using amphetamines intermittently for both diet and mood-elevating effects. A few days before she became ill she started to ingest $10 \mathrm{mg}$. tranylcypromine tablets once or twice a day. She had taken one amphetamine and one tranylcypromine tablet just before going on duty the night that she took ill. This was the first time that both drugs had been taken together. The patient had obtained the drugs as samples in the hospital clinics.

The patient recovered completely. Her mental status during convalescence was normal and she gave us no reason to doubt her story.

At the time of her admission extensive blood, urine, spinal-fluid, and stool cultures were negative. A lumbar puncture had been normal. A variety of drugs were looked for, including salicylates. None were found. Unfortunately no assay for amphetamine or tranylcypromine was done.

I believe that this case represents an example of near-fatal hyperpyrexia caused by the ingestion of therapeutic amounts of tranylcypromine and amphetamine. In the full appraisal of the clinical usefulness of antidepressant agents, such cases must be given proper consideration.-I am, etc.,

Johns Hopkins Hospital,

Maryland, U.S.A.

EDMUND LEWIS.

\section{REFERENCES}

- Stanley, B., and Pal, N. R., Brit. med. F., 1964, 2, 1011. W., ibid., 1964, 2, 1466

' Bowen, L. W., ibid., 1964, 2, 1466. 921.

\section{Oral Contraceptives and Liver Injury}

SIR,-In your leading article (29 May, p. 1391) you refer to the enormous numbers of women who are now taking oral contraceptives, and, of course, very many of these women are taking them without medical indications. Those of us who are concerned about the possible long-term effects of this wholesale use of hormones will not be very greatly reassured by your article. It may be true that liver damage is the least of the risks (I think there are more important possibilities), or it may be that there is no danger at all, but surely the evidence is insufficient to warrant the conclusions you draw.

The investigations reported by Dr. G. I. M. Swyer and Dr. V. Little (29 May, p. 1412) are extremely valuable, but we cannot say the risk is negligible merely because twelve women have taken these pills for a few years without demonstrable liver damage. Would it not have been as logical to have argued, say ten years ago, that because twelve men had smoked heavily for three to six years and none had developed cancer, there was there- fore no harm in smoking ? Such a conclusion would plainly have been dangerously incorrect, but it would have had this in common with the other conclusion: it would have been in accordance with what people wanted to hear and to believe.-I am, etc.,

Banbury, Oxon.

J. M. Gate.

\section{Action of Bismuth Aluminate}

SIR,-The paper by Dr. S. G. Flavell Matts and his colleagues (20 March, p. 753) demonstrates statistically significant clinical results in favour of bismuth aluminate. Although the exact mode of action of this new bismuth compound is not understood, the authors' hypothesis suggesting that the good therapeutic results may be due to a coating effect providing a local antipepsin action at the site of the ulcer is an interesting possibility.

Bismuth aluminate has been used in this department in following up our studies on the effect of aspirin on gastric secretion. ${ }^{1}$ Our initial objective was to determine whether bismuth aluminate would provide protection against gastric mucosal damage caused by the administration of aspirin. Our results in this respect were negative, but some of our experimental findings may have a bearing on the hypothesis put forward by Matts and his colleagues.

In one series of our cat experiments the animals were given either bismuth aluminate or aspirin, or a combination of the two drugs, prior to histamine infusion and tests for gastric function. The experimental technique was basically the same as that reported in our paper on histamine secretory tests in cats. ${ }^{2}$ The bismuth aluminate or aspirin was suspended in about $50 \mathrm{ml}$. of water and injected into the stomach. After $1 \frac{1}{2}$ hours the stomach was opened and all residue of the drug was removed.

Intense histamine stimulation was started and the gastric juice collected for the next $3 \frac{1}{2}$ to 4 hours. At the conclusion of the experiment the stomach was opened and in 13 cats where bismuth aluminate had been administered alone a film of the bismuth compound was found to be clinging to the gastric mucosa even though the drug had apparently been previously removed from the stomach.

In another series of experiments gastric juice was obtained from dogs; peptic activity was measured and subsequently bismuth aluminate was added at a concentration of $0.05 \mathrm{~g}$. per ml. Pepsin estimations were repeated at various $p H$ levels and it was found that peptic activity was reduced by bismuth aluminate at all $\mathrm{pH}$ levels from 0.5 to 6.5. The gastric juice used in these experiments was obtained from denervated Heidenhain pouches and either because of this or because of species difference there was much less peptic activity than in man. This suggests that to demonstrate the antipeptic effect of bismuth aluminate on gastric juice from the lumen of the stomach in man a larger dose would be needed than that used by Matts and his colleagues. Nevertheless, our results provide some confirmation of the antipeptic action previously demonstrated in vitro. ${ }^{3}$

Thus it appears that bismuth aluminate could certainly provide a coating of the gastric mucosa, and this may exert a local antipeptic effect of a sufficient order to prevent autodigestion at the site of the ulcer, even though it may not be detectable by biochemical analysis of a sample of gastric juice from the lumen. In this context it is of interest that surface mucus can have a $p \mathrm{H}$ of up to 9 or 10 while the $p \mathrm{H}$ of the stomach contents may be less than 5 .
As Matts and his colleagues suggest, hyperacidity alone may be relatively unimportant in connexion with the origin of peptic ulceration which is almost certainly due to autodigestion by acid-pepsin and possibly involving other gastric processes. Peptic inactivation is thus important, and if bismuth aluminate exerts a local antiproteolytic action at the site of the ulcer, following coating of the gastric mucosa, this could certainly account for the good clinical effect demonstrated in the double-blind trial.-I am, etc.,

$$
\text { St. Vincent's Hospital, G. W. MiLton. }
$$$$
\text { Sydney, South Wales, Australia. }
$$

\section{REFERENCES}

1 Lynch, A., Shaw, H., and Milton, G. W., Gut, $1964,5,230$. W.,
Milton, G. W., Skyring, A. K., and George,
E. P., Gastroenterology, E. P., Gastroenterology, 1963, 44, 642. George,
Bateson, P. R., J. Pharm. Pharmacol., 1958, 10,
123.

\section{Sodium Fluoride and Cell Growth}

SIR,-Professor W. D. Armstrong and his colleagues (29 May, p. 1435) have now broadened the scope of their earlier observations (20 February, p. 486) which refuted the evidence of Berry and Trillwood ${ }^{1}$ for the inhibition of cell growth in vitro by small amounts of sodium fluoride incorporated in the culture medium. Dr. Berry and Mr. Trillwood (20 March, p. 793) had disputed the validity of the earlier observations of Armstrong and his colleagues on the ground that their own data were based upon cultures extending over three- to four-cell duplications, which was a better test of growth inhibition than the one-cell duplication originally examined by Armstrong and his colleagues.

The more recent observations of Armstrong and his colleagues go some way toward answering these objections, although only a small number of selected HeLa-cell clones were studied. Nevertheless, since Berry and Trillwood had maintained that their original biological observation had still not been validly refuted, it seemed important to repeat their own experiments-i.e., growth tests of HeLa cells growing as a monolayer attached to glass for at least four cell duplications during a week. I have now performed five such experiments with cells cultured for over six cell duplications during a week and I am unable to confirm their observation of a growth inhibition by sodium fluoride.

Five growth experiments have been performed in this laboratory with HeLa cells

Number of HeLa Cells $\left(\times 10^{6}\right)$ after 1 Week's Growth With and Without Sodium Fluoride (1 p.p.m.).

\begin{tabular}{|c|c|c|}
\hline $\begin{array}{l}\text { Experiment } \\
\text { Number }\end{array}$ & $\begin{array}{l}\text { Control } \\
\text { Cultures }\end{array}$ & $\begin{array}{l}\text { Fluoride } \\
\text { Cultures }\end{array}$ \\
\hline 1 & $\begin{array}{l}3 \cdot 77 \\
3 \cdot 75\end{array}$ & $\begin{array}{l}3 \cdot 87 \\
4 \cdot 02\end{array}$ \\
\hline 2 & $\begin{array}{l}4 \cdot 65 \\
4 \cdot 90\end{array}$ & $\begin{array}{l}4 \cdot 82 \\
4 \cdot 80\end{array}$ \\
\hline 3 & $\begin{array}{l}5 \cdot 02 \\
4 \cdot 17\end{array}$ & $\begin{array}{l}4 \cdot 22 \\
4 \cdot 12\end{array}$ \\
\hline 4 & $\begin{array}{l}4 \cdot 30 \\
4 \cdot 80\end{array}$ & $\begin{array}{l}4 \cdot 50 \\
4 \cdot 00\end{array}$ \\
\hline 5 & $\begin{array}{l}4.90 \\
4 \cdot 60\end{array}$ & $\begin{array}{l}4 \cdot 50 \\
4 \cdot 30\end{array}$ \\
\hline Mean & $4 \cdot 486$ & $4 \cdot 315$ \\
\hline
\end{tabular}

Difference between means $=0 \cdot 171 \pm 0 \cdot 120(4 \% \pm$
$2 \cdot 8 \%)$. 